\title{
Methods and timing of biliary drainage for acute cholangitis: Tokyo Guidelines
}

\author{
Masato Nagino $^{1}$, Tadahiro Takada ${ }^{2}$, Yoshifumi Kawarada ${ }^{3}$, Yuji Nimura ${ }^{1}$, Yuichi Yamashita ${ }^{4}$, \\ Toshio Tsuyuguchi ${ }^{5}$, Keita Wada ${ }^{2}$, Toshihiko Mayumi ${ }^{6}$, Masahiro Yoshida ${ }^{2}$, Fumihiko Miura 2 , \\ Steven M. Strasberg ${ }^{7}$, Henry A. Pitt ${ }^{8}$, Jacques Belghiti ${ }^{9}$, Sheung-Tat Fan ${ }^{10}$, Kui-Hin Liau ${ }^{11}$, Giulio Belli ${ }^{12}$, \\ Xiao-Ping Chen ${ }^{13}$, Edward Cheuck-Seen Lai ${ }^{14}$, Benny P. Philippi ${ }^{15}$, Harjit Singh ${ }^{16}$, and Avinash Supe ${ }^{17}$ \\ ${ }^{1}$ Division of Surgical Oncology, Department of Surgery, Nagoya University Graduate School of Medicine, 65 Tsurumai-cho, Showa-ku, \\ Nagoya 466-8550, Japan \\ ${ }^{2}$ Department of Surgery, Teikyo University School of Medicine, Tokyo, Japan \\ ${ }^{3}$ Mie University School of Medicine, Mie, Japan \\ ${ }^{4}$ Department of Surgery, Fukuoka University Hospital, Fukuoka, Japan \\ ${ }^{5}$ Department of Medicine and Clinical Oncology, Graduate School of Medicine Chiba University, Chiba, Japan \\ ${ }^{6}$ Department of Emergency Medicine and Critical Care, Nagoya University School of Medicine, Nagoya, Japan \\ ${ }^{7}$ Department of Surgery, Washington University in St Louis and Barnes-Jewish Hospital, St Louis, USA \\ ${ }^{8}$ Department of Surgery, Indiana University School of Medicine, Indianapolis, USA \\ ${ }^{9}$ Department of Digestive Surgery and Transplantation, Hospital Beaujon, Clichy, France \\ ${ }^{10}$ Department of Surgery, The University of Hong Kong, Pokfulam, Hong Kong, China \\ ${ }^{11}$ Department of Surgery, Tan Tock Seng Hospital / Hepatobiliary Surgery, Medical Centre, Singapore, Singapore \\ ${ }^{12}$ Department of General and HPB Surgery, Loreto Nuovo Hospital, Naples, Italy \\ ${ }^{13}$ Department of Surgery and Hepatic Surgery Center, Tongi Hospital of Tongi Medical College, Huazhong University of Science and \\ Technology, Wuhan, China \\ ${ }^{14}$ Pedder Medical Partners, Hong Kong, China \\ ${ }^{15}$ Department of Surgery, University of Indonesia, Cipto Mangunkusumo National Hospital, Jakarta, Indonesia \\ ${ }^{16}$ Hepatopancreatobiliary Surgery Unit, Department of Surgery, Hospital Sepayang, Kuala Lumpur, Malaysia \\ ${ }^{17}$ HPB Surgery and Liver Transplantation, Seth GS Medical College and KEM Hospital, Mumbai, India
}

\begin{abstract}
Biliary drainage is a radical method to relieve cholestasis, a cause of acute cholangitis, and takes a central part in the treatment of acute cholangitis. Emergent drainage is essential for severe cases, whereas patients with moderate and mild disease should also receive drainage as soon as possible if they do not respond to conservative treatment, and their condition has not improved. Biliary drainage can be achieved via three different routes/procedures: endoscopic, percutaneous transhepatic, and open methods. The clinical value of both endoscopic and percutaneous transhepatic drainage is well known. Endoscopic drainage is associated with a low morbidity rate and shorter duration of hospitalization; therefore, this approach is advocated whenever it is applicable. In endoscopic drainage, either endoscopic nasobiliary drainage (ENBD) or tube stent placement can be used. There is no significant difference in the success rate, effectiveness, and morbidity between the two procedures. The decision to perform endoscopic sphincterotomy (EST) is made based on the patient's condition and the number and diameter of common bile duct stones. Open drainage, on the other hand, should be applied only in patients for whom endoscopic or percutaneous transhepatic drainage is contraindicated or has not been successfully performed. Cholecystectomy is recommended in patients with gallbladder stones, following the resolution of acute cholangitis with med-
\end{abstract}

Offprint requests to: $\mathrm{M}$. Nagino

Received: May 31, 2006 / Accepted: August 6, 2006 ical treatment, unless the patient has poor operative risk factors or declines surgery.

Key words Cholangitis - Biliary · Drainage - Endoscopy · Percutaneous $\cdot$ Sphincterotomy $\cdot$ Guidelines

\section{Introduction}

Acute cholangitis presents with a wide spectrum of severity, ranging from relatively mild cases to severe cases associated with hypotension and disturbed consciousness. It has been reported that when no appropriate biliary drainage was available $20-30$ years ago, the mortality of acute cholangitis with conservative treatment was extremely high (Table 1 ). There has been no randomized controlled trial (RCT) comparing conservative treatment and biliary drainage. However, it is evident that many patients with acute cholangitis cannot be saved by conservative treatment alone.

Biliary drainage is a radical method to relieve cholestasis, a cause of acute cholangitis, and takes a central part in the treatment of acute cholangitis. This article reviews articles in the literature on biliary drainage methods and discusses the methods and timing of biliary drainage for acute cholangitis, in terms of the principles 
of evidence-based medicine, in a question and recommendation format. The recommendations are defined according to discussion at Tokyo Consensus Meeting.

\section{Q1. How do we select the mode of biliary drainage - endoscopic vs percutaneous vs open?}

\section{Endoscopic biliary drainage (recommendation A). \\ Percutaneous transhepatic biliary drainage (rec- ommendation B).}

Biliary drainage can be achieved by three different procedures: endoscopic, percutaneous transhepatic, and open drainage. The safety and usefulness of endoscopic drainage have been proved by many studies (level $2 b)^{3}$ (level 4). ${ }^{4-6}$ A randomized controlled trial (RCT) ${ }^{3}$ was conducted to compare endoscopic and open drainage in 82 patients with severe acute cholangitis with hypotension and disturbed consciousness. This RCT demonstrated that the morbidity and mortality of endoscopic nasobiliary drainage (ENBD) + endoscopic sphincterotomy (EST; $n=41$ ) were significantly lower than those of T-tube drainage under laparotomy $(n=41)$, concluding that endoscopic drainage was safer and more effective than open drainage (Table 2) (level 2b). Although there are no recent reports on open drainage, Sawyer and Jones ${ }^{7}$ describe that endoscopic or interventional radiological drainage is superior to open drainage.

Chen et al. ${ }^{8}$ performed percutaneous transhepatic biliary drainage (PTBD) in 56 acute cholangitis patients, and observed noticeably improved clinical conditions in 46 patients $(82.1 \%)$, with disappearance of fever within 18-24h (level 4). Pessa et al. ${ }^{9}$ also performed PTBD, in 42 acute cholangitis patients, and reported a success rate of $100 \%$, morbidity rate of $7 \%$, and mortality rate

Table 1. Mortality of acute cholangitis patients peceiving conservative treatment

\begin{tabular}{lc}
\hline Author & $\begin{array}{c}\text { Mortality rate with } \\
\text { conservative therapy }\end{array}$ \\
\hline O'Connor et al. $^{1}$ & $87 \%$ \\
Welch and Donaldson $^{2}$ & $100 \%$ \\
\hline
\end{tabular}

of $5 \%$ (level 4). Though the usefulness of percutaneous transhepatic drainage is widely recognized, all of the previous reports were retrospective case-series studies (level 4)..$^{8-16}$

As there is no RCT comparing endoscopic and percutaneous drainage, a definitive conclusion on the better procedure has not been reached. However, considering the rare occurrence of serious complications such as intraperitoneal hemorrhage and biliary peritonitis, ${ }^{4-6}$ and the shorter duration of hospitalization, ${ }^{17}$ endoscopic drainage is preferred whenever it is available and applicable (level 4) ${ }^{17,18}$ (level 3a). ${ }^{19-21}$ In short, as both procedures require experienced hands, the drainage method selected should be contingent upon the availability of resources and staff, so that the drainage can be delivered successfully with a good outcome.

\section{Results at Tokyo Consensus Meeting}

Most panelists from Japan and abroad preferred endoscopic drainage (Fig. 1).

Q2. What procedure should be used for endoscopic biliary drainage? External (nasobiliary drainage) or internal drainage? Also, what are the criteria for the addition of endoscopic sphincterotomy (EST) vs no EST?

Either ENBD or biliary tube stent placement can be used.

Addition of EST should be determined according to the patient's condition and the operator's skill.

Two RCTs (level 2b) ${ }^{22,23}$ comparing ENBD and biliary tube stent placement showed no significant difference in success rate, effectiveness, or morbidity. Another study ${ }^{22}$ revealed that the incidence of tube troubles such as removal of the tube by patients themselves tended to be higher with ENBD, and the patient's level of discomfort was significantly lower with the stent placement. From these findings, for patients who are likely to remove the ENBD tube by themselves, stent placement is preferable. ${ }^{22}$

Table 2. Drainage for acute cholangitis: endoscopic vs open drainage ${ }^{3}$

\begin{tabular}{lccc}
\hline Results & Endoscopic & Open & Relative risk reduction \\
\hline Mortality & $10 \%$ & $32 \%$ & $69 \%$ \\
Complication & $34 \%$ & $66 \%$ & $48 \%$ \\
Artificial respiration installation & $29 \%$ & $63 \%$ & $54 \%$ \\
\hline
\end{tabular}




\section{Question 1}

\section{How do we select the mode of biliary drainage? (Which procedure do you prefer?)}

- Endoscopi drainage

a. Percutaneous drainage

3 Open drainage

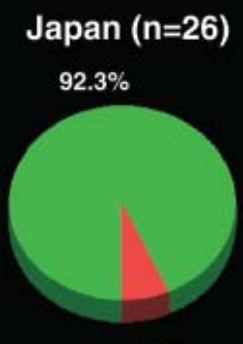

Oversea $(n=24)$

$87.5 \%$

$7.7 \%$

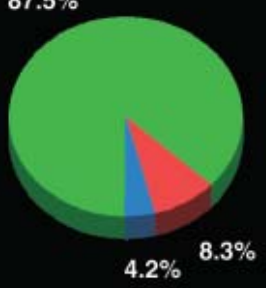

Fig. 1.

\section{Question 2}

\section{Which procedure should be used? (Which procedure do you prefer?)}

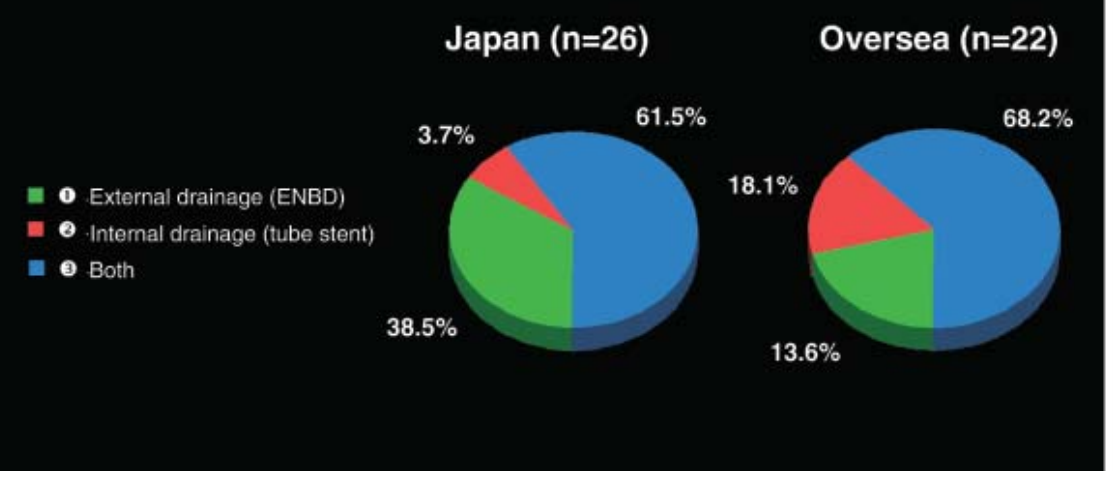

Fig. 2.

Endoscopic biliary drainage methods applicable for choledocholithiasis-induced acute cholangitis, the most frequently encountered disease in the clinical setting, include EST alone, EST followed by lithotomy, and ENBD or biliary tube stent placement using a plastic tube with or without EST, but there is no RCT comparing these methods. There are two reports of case-series studies (level 4), ${ }^{24,25}$ which examined whether or not EST should be added to ENBD or biliary tube stent placement (Table 3). They indicated that there was no significant difference in the success rate and effectiveness of drainage between these two methods, but complications including hemorrhage were observed more frequently in patients who underwent EST. Accordingly, for critically ill patients in whom emergent drainage is essential, ENBD or stent placement without EST is preferable, and one-stage choledocholithotomy requiring EST is not recommended. The performance of choledocholithotomy following EST should be determined by taking both the patient's condition and the number and diameter of stones into account.

\section{Results at Tokyo Consensus Meeting}

About two-thirds of the panelists agreed that either ENBD or biliary tube stent placement could be used (Fig. 2). As to the addition of EST, more than half of the panelists mentioned that EST was essential in principle, but that its use depended on the patient's condition and the operator's skill (Fig. 3). 


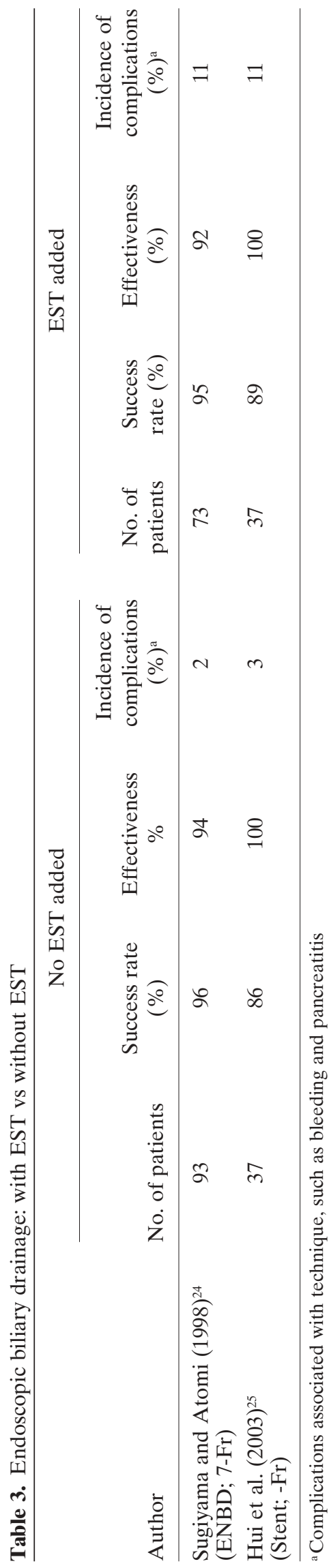

\section{Q3. What are the indications for open drainage?}

Open drainage should only be used in patients for whom endoscopic or percutaneous transhepatic drainage is contraindicated or those in whom it has been unsuccessfully performed. In such difficult conditions, the primary goal is to decompress the biliary tract expeditiously. It is important to emphasize the shortening of operative time and the minimizing of surgical invasiveness. For these reasons, it is recommended to complete the operation quickly by placing a $\mathrm{T}$-tube without spending a long time on lithotomy ${ }^{26}$ (level 4).

\section{Q4. Is prophylactic cholecystectomy necessary after choledocholithiasis has been successfully treated in acute cholangitis?}

Cholecystectomy is indicated after the resolution of acute cholangitis (recommendation B).

Boerma et al. ${ }^{27}$ conducted an RCT (level 2b) to assess the clinical value of prophylactic laparoscopic cholecystectomy in patients whose choledocholithiasis was successfully treated with EST (all patients had gallbladder stones). Symptoms related to cholecystitis appeared in 27 of 59 patients (46\%) who had not undergone prophylactic laparoscopic cholecystectomy, and eventually 22 of the 27 underwent cholecystectomy. Thus, Boerma et al. concluded that prophylactic cholecystectomy was of clinical value.

It has been reported that the incidence of cholecystitis in patients whose gallbladders were left with stones after EST was $7.6 \%-22 \%(\text { level } 2 b)^{28-31}$ (Table 4). This incidence is not significantly different from the incidence of cholecystitis in patients with asymptomatic cholecystolithiasis $(15.5 \%-51 \%)$; therefore, prophylactic cholecystectomy might be unnecessary. The objective here is to prevent the subsequent recrudescence of severe acute cholangitis or acute cholecystitis with attending high fatality. In patients with an acalculous gallbladder, the incidence of cholecystitis is low, around $1 \%$, so that no cholecystectomy is required (level $2 \mathrm{~b})^{28-31}$ (Table 4).

\section{Results of discussion about the "Timing of biliary} drainage" at the Tokyo Consensus Meeting

As to the issue of timing, there are few references leading to evidence-based recommendations; therefore, attempts were made to obtain consensus from the panelists after the discussion.

Consensus was reached regarding severe (Fig. 4) and mild acute cholangitis (Fig. 6), but not on moderate acute cholangitis (Fig. 5). 


\section{Question 3}

For biliary drainage, not for stone removal, do you prefer addition of EST? (Do you think EST is essential?)

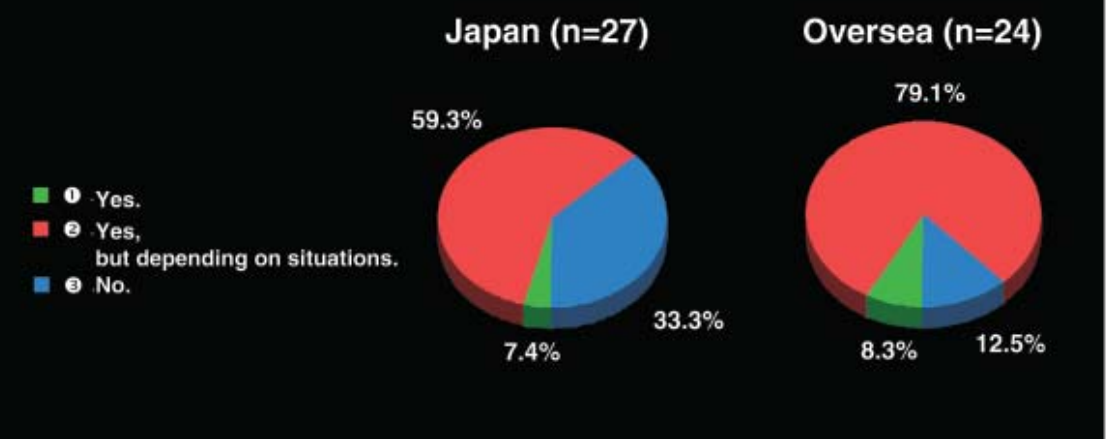

Fig. 3.

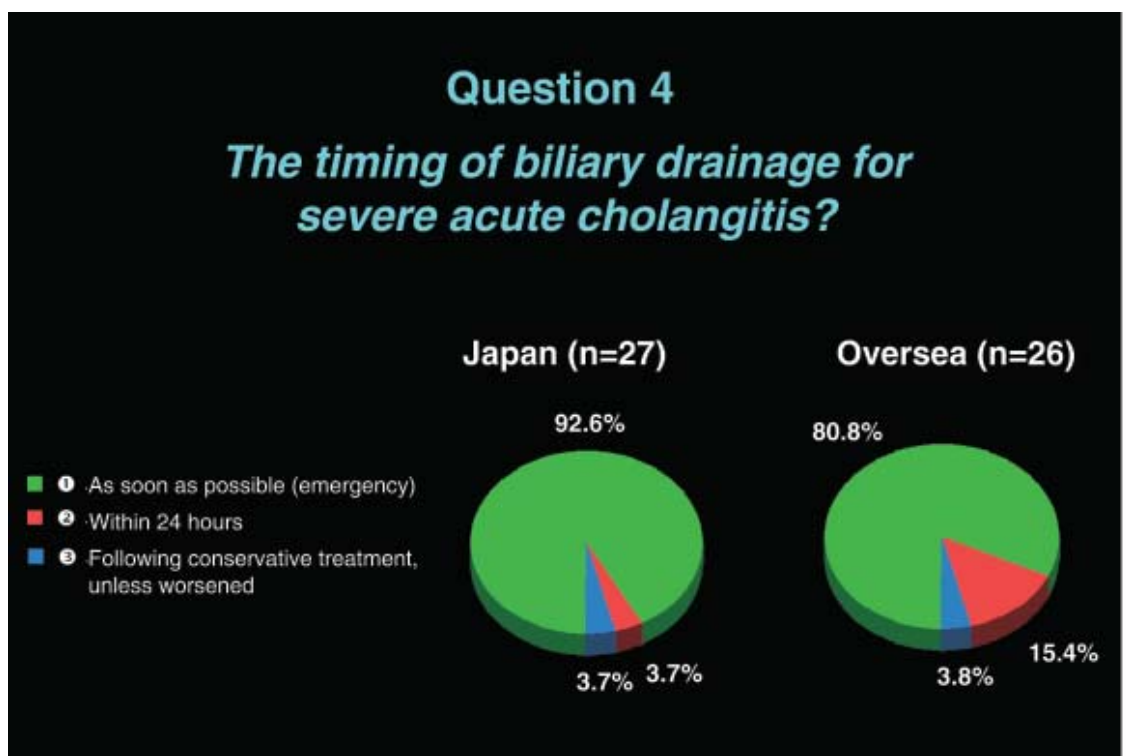

Fig. 4.

Table 4. Incidence of acute cholecystitis after endoscopic treatment of choledocholithiasis

\begin{tabular}{lcc}
\hline Calculous gallbladder & Acalculous gallbladder & $\begin{array}{c}\text { Average observation } \\
\text { period (years) }\end{array}$ \\
\hline $5.8 \%(11 / 190)$ & - & $6.8^{28 a}$ \\
$7.6 \%(34 / 448)$ & $1.2 \%(3 / 246)$ & $7.5^{29}$ \\
$12 \%(2 / 17)$ & $0 \%(0 / 15)$ & $14.5^{30}$ \\
$22 \%(7 / 32)$ & $1 \%(1 / 88)$ & $10.2^{31}$ \\
\hline
\end{tabular}

a Whether or not the whole population had calculous gallbladders is unknown 


\section{Question 5-1}

The timing of biliary drainage for moderate acute cholangitis?

Japan $(n=28)$

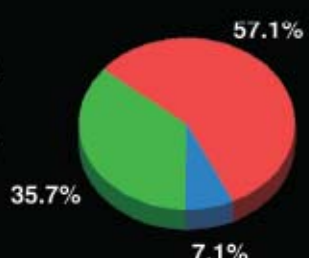

Oversea $(\mathbf{n}=\mathbf{2 6})$

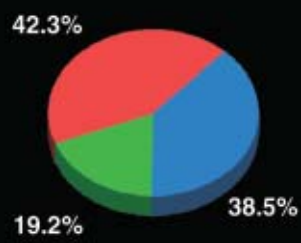

a

- 0 As soon as possible (emergency)

- 2 . Within 24 hours

a 3 Following conservative treatment. unless worsened

(7.1\%

\section{Question 5-2}

The timing of biliary drainage for moderate acute cholangitis?

- As soon as possible (emergency)

a . Within 12 hours

[1 3 Following conservative treatment, unless worsened
Japan $(\mathbf{n = 2 9 )}$

$72.4 \%$

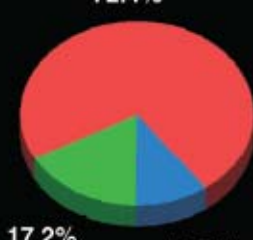

$10.3 \%$
Oversea $(\mathbf{n}=24)$

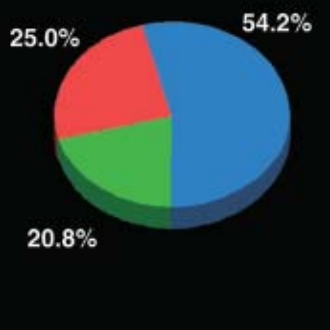

Fig. 5.

\section{Question 6}

The timing of biliary drainage for mild acute cholangitis?

$$
\text { Japan }(n=29)
$$

$$
\text { Oversea }(n=25)
$$

- As soon as possible (emergency)

a Within 12 hours

- 3 Following conservative treatment, unless worsened
$96.6 \%$

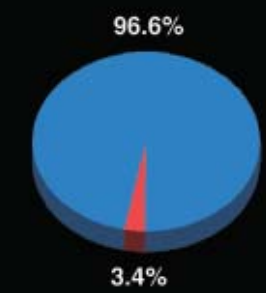

$3.4 \%$
$88.0 \%$

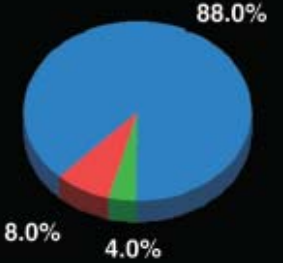


Acknowledgments. We would like to express our deep gratitude to the Japanese Society for Abdominal Emergency Medicine, the Japan Biliary Association, and the Japanese Society of Hepato-Biliary-Pancreatic Surgery, who provided us with great support and guidance in the preparation of the Guidelines. This process was conducted as part of the Project on the Preparation and Diffusion of Guidelines for the Management of Acute Cholangitis (H-15-Medicine-30), with a research subsidy for fiscal 2003 and 2004 (Integrated Research Project for Assessing Medical Technology), sponsored by the Japanese Ministry of Health, Labour, and Welfare.

We also truly appreciate the panelists who cooperated with and contributed significantly to the International Consensus Meeting, held on April 1 and 2, 2006.

\section{References}

1. O'Connor MJ, Schwartz ML, McQuarrie DG, Sumer HW. Acute bacterial cholangitis: an analysis of clinical manifestation. Arch Surg 1982;117:437-41. (level 4)

2. Welch JP, Donaldson GA. The urgency of diagnosis and surgical treatment of acute suppurative cholangitis. Am J Surg 1976;131: 527-32. (level 4)

3. Lai EC, Mok FP, Tan ES, Lo CM, Fan ST, You KT, et al. Endoscopic biliary drainage for severe acute cholangitis. N Engl J Med 1992;24:1582-6. (level 2b)

4. Leung JW, Chung SC, Sung JJ, Banez VP, Li AK. Urgent endoscopic drainage for acute suppurative cholangitis. Lancet 1989; 10:1307-9. (level 4)

5. Boender J, Nix GA, de Ridder MA, Dees J, Schutte HE, van Buuren HF, et al. Endoscopic sphincterotomy and biliary drainage in patients with cholangitis due to common bile duct stones. Am J Gastroenterol 1995;90:233-8. (level 4)

6. Lau JY, Chung SC, Leung JW, Ling TK, Yung MY, Li AK. Endoscopic drainage aborts endotoxaemia in acute cholangitis. Br J Surg 1996;83:181-4. (level 4)

7. Sawyer RG, Jones RS. Acute cholangitis. In: Cameron JL, editor. Current surgical therapy. 8th ed. 2004: Elsevier: New York. 40710. (level 4)

8. Chen MF, Jan YY, Lee TY. Percutaneous transhepatic biliary drainage for acute cholangitis. Int Surg 1987;72:131-3. (level 4)

9. Pessa ME, Hawkins IF, Vogel SB. The treatment of acute cholangitis: percutaneous transhepatic biliary drainage before definitive therapy. Ann Surg 1987;205:389-92. (level 4)

10. Lois JF, Gomes AS, Grace PA, Deutsch LS, Pitt HA. Risks of percutaneous transhepatic drainage in patients with cholangitis. Am J Roentgenol AJR 1987;148:367-71. (level 4)

11. Szabo S, Mendelson MH, Mitty HA, Bruckner HW, Hirschman SZ. Infections associated with transhepatic biliary drainage devices. Am J Med 1987;82:921-6. (level 4)

12. Audisio RA, Bozzetti F, Severini A, Bellegotti L, Bellomi M, Cozzi G, et al. The occurrence of cholangitis after percutaneous biliary drainage: evaluation of some risk factors. Surgery 1988; 103:507-12. (level 4)

13. Clouse ME, Evans D, Costello P, Alday M, Edwards SA, McDermott WV Jr, et al. Percutaneous transhepatic biliary drainage: complications due to multiple duct obstructions. Ann Surg 1983;198:25-9. (level 4)

14. Cohan RH, Illescas FF, Saeed M, Perlmutt LM, Braun SD, Newman GE, et al. Infectious complications of percutaneous biliary drainage. Invest Radiol 1986;21:705-9. (level 4)
15. Audisio RA, Morosi C, Bozzetti F, Cozzi G, Bellomi M, Pisani P, et al. The outcome of cholangitis after percutaneous biliary drainage in neoplastic jaundice. HBP Surg 1993;6:287-93. (level 4)

16. Nomura T, Shirai Y, Hatakeyama K. Bacteribilia and cholangitis after percutaneous transhepatic biliary drainage for malignant biliary obstruction. Dig Dis Sci 1999;44:542-6. (level 4)

17. Sugiyama M, Atomi Y. Treatment of acute cholangitis due to choledocholithiasis in elderly and younger patients. Arch Surg 1997;132:1129-33. (level 4)

18. Kadakia SC. Biliary tract emergencies. Med Clin North Am 1993;77:1015-36. (level 4)

19. Lee DWH, Chung SCS. Biliary infection. Baillieres Clin Gastroenterol 1997;11:707-24. (level 3a)

20. Lipsett PA, Pitt HA. Acute cholangitis. Surg Clin North Am 1990;70:1297-312. (level 3a)

21. Hanau LH, Steigbigel NH. Acute cholangitis. Infect Dis Clin North Am 2000;14:521-46. (level 3a)

22. Lee DW, Chan AC, Lam YH, Ng EK, Lau JY, Law BK, et al. Biliary decompression by nasobiliary catheter or biliary stent in acute suppurative cholangitis: a prospective randomized trial. Gastrointest Endosc 2002;56:361-5. (level 2b)

23. Sharma BC, Kumar R, Agarwal N, Sarin SK. Endoscopic biliary drainage by nasobiliary drain or by stent placement in patients with acute cholangitis. Endoscopy 2005;37:439-43. (level 2b)

24. Sugiyama M, Atomi $\mathrm{Y}$. The benefits of endoscopic nasobiliary drainage without sphincterotomy for acute cholangitis. Am J Gastroenterol 1998:93:2065-8. (level 4)

25. Hui CK, Lai KC, Yuen MF, Ng M, Chan CK, Hu W, et al. Does the addition of endoscopic sphincterotomy to stent insertion improve drainage of the bile duct in acute suppurative cholangitis. Gastrointest Endosc 2003;58:500-4. (level 4)

26. Saltzstein EC, Peacock JB, Mercer LC. Early operation for acute biliary tract stone disease. Surgery 1983;94:704-8. (level 4)

27. Boerma D, Rauws EA, Keulemans YC, Janssen YC, Bolwerk CJ, Timmer R, et al. Wait-and-see policy or laparoscopic cholecystectomy after endoscopic sphincterotomy for bile duct stones: a randomized trial. Lancet 2002;360:739-40. (level 2b)

28. Costamagna G, Tringali A, Shah SK, Mutignani M, Zuccala G, Perri V. Long-term follow-up of patients after endoscopic sphincterotomy for choledocholithiasis, and risk factors for recurrence. Endoscopy 2002;34:273-9. (level 2b)

29. Ando T, Tsuyuguchi T, Saito M, Ishihara T, Yamaguchi T, Saisho H. Risk factors for recurrent bile duct stones after endoscopic papillotomy. Gut 2003;52:116-21. (level 2b)

30. Sugiyama M, Atomi M. Risk factors predictive of late complications after endoscopic sphincterotomy for bile duct stones: longterm (more than 10 years) follow-up study. Am J Gastroenterol 2002;97:2763-7. (level 2b)

31. Tanaka M, Takahata S, Konmi H, Matsunaga H, Yokohata K, Takeda T, et al. Long-term consequence of endoscopic sphincterotomy for bile duct stones. Gastrointest Endosc 1998;48:465-9. (level 2b)

\section{Discussion at the Tokyo Consensus Meeting}

\section{Selection of the mode of biliary drainage}

Philippus C. Bornman (South Africa): Thank you very much for your presentation, Dr. Nagino. The first question is "How do we select the mode of biliary drainage?" and I would like to focus only on choledocholithiasis and also then bearing in mind that expertise, as well as facilities, are equal at a given institution. So we are going to ask them three questions: should it be endoscopic drainage, percutaneous, or open drainage. But before 
we do that, could we please have some comments from our panelists both overseas and local please.

Masato Nagino (Japan): Before selecting such kind of interpretation I do keep in mind the level of biliary stenosis, proximal or distal.

Philippus C. Bornman: Yes, I think that it is an important one and maybe we should - we will certainly bear that in mind and we should come back to that, but if we exclude patients with biliary strictures and we are only talking about patients with choledocholithiasis that is our first question please. No infected stones - we will get to that later on.

Edward C.S. Lai (Hong Kong): I think to start off with, it will be important to differentiate between patients with common bile duct stone and those without. Because these are two very important situations in which the management can be totally different. I know that, Mr. Chairman, you are trying to confine it to stones. But I would like to have a bit of discussion on non-stone situations as well at the end if you have time.

Philippus C. Bornman: Please, we certainly will do that and I think we will take it immediately after we have made our first choice. OK, shall we then go to the vote and shall we start with our Japanese panel of experts and they will indicate to us one, two, or three. Could you please vote now; full house. Good, right, let us first look at the Japanese results. That is not entirely surprising, and then onto the overseas experts (refer to Fig. 1).

From this we can conclude that, in the setting of patients with bile duct stones, without intrahepatic stones without strictures, the preferred procedure is endoscopic drainage. I would like to get some comments. I can see $8 \%$ mentioned percutaneous drainage, so there are clearly some situations where the percutaneous drainage will be preferred. Can we get some comments from those who joined the $8 \%$ group please?

Serafin C. Hilvano (Philippines): We start off with a compromise, in our institution. We usually prefer the percutaneous drainage first then shift to an endoscopic, enlarging the route - the access - with the use of a cholangioscope so that is sort of a compromise. We start with a percutaneous then shift to a cholangioscope.

Philippus C. Bornman: May I ask, do you have similar endoscopic facilities at your institution or are you more familiar with the percutaneous techniques and its availability?

Serafin C. Hilvano: That is, our colleagues in surgery still lack the skill that our Japanese colleagues have. That is probably the limitation that we are limited to.

Philippus C. Bornman: Thank you for that comment. Can we have some more comments on the percutaneous approach? Joseph, would you like to take it up. ${ }^{2}$ Can I ask-can I put it to you this way. At our institution although we have both available, we tend to go for the percutaneous technique in a small select [group] of patients with severe cholangitis and those patients with comorbid disease, because to use conscious sedation and go to a facility at which you do not have all those facilities for resuscitation, we feel that, perhaps, a percutaneous approach in those patients perhaps is a safer procedure, given our facilities and the risks of bleeding and so on; so I will put it as a provocative statement. The other point, of course, is that percutaneous drainage is a secure form of drainage, you are sure that this system is drained, whereas sometimes with the endoscopic one, and we will come to that, you are not always sure if your nasobiliary drain is in position or your stent is functioning properly. Perhaps we can have some comments on that please. Henry, I saw you moving your head sideways - could you comment on that please. $^{2}$

Henry A. Pitt (USA): There may be, I think, some rare circumstances, local circumstances, where percutaneous would be an advantage here. But I think that, all else being equal, which is how you asked the question, equal expertise, I agree with the vast majority.

\section{Internal (tube stent) or external (nasobiliary) drainage}

Philippus C. Bornman: The second question we will address is: "Which procedure do you prefer, internal (tube stent) or external (nasobiliary drainage)?" And again I would like to have some comments from our panelists please.

Horst Neuhaus (Germany): I think it depends on the viscosity of the bile. So if you have pus in the biliary system, then I would not rely on an endoprosthesis because it will quickly block with the continuous cholangitis, and I would strongly recommend inserting a nasobiliary probe.

Philippus C. Bornman: Can I just ask a further question on that comment you made? Are those usually the patients with severe cholangitis? So it is the severe ones that you will not only rely on an internal stent?

Masao Tanaka (Japan): I strongly agree with Doctor Neuhaus's comment. When there is so much purulent bile, ENBD is the priority, but depending on where the stricture is and how much stone is there. When we do not know the stricture position, ENBD is better for future cholangiography. However, for confused patients or very old patients who cannot understand, they may actually pull off the catheter, so in that case a stent is better.

Sheung-Tat Fan (Hong Kong): I tend to disagree that the nasobiliary drainage is good for a patient with pus in the common bile duct. In that situation I doubt whether it could drain the part very well. So my question to Doctor Neuhaus is, have you ever really drained a bile duct with a lot of thick pus effectively by nasobili- 
ary drainage? I think that in this situation we should resort to surgery as soon as possible.

Horst Neuhaus: Okay, you did not give another option to do endoscopic sphincterotomy. I think this is your next question. So if we have pus in the duct, we do sphincterotomy - we clear the duct and then we would insert a nasobiliary probe, but this was not included here in this selection.

Henry A. Pitt: Should not the size of the stent be a factor in addition? I mean, are you not limited somewhat with the naso-biliary?

Philippus C. Bornman: Yes, you use the 10-French nasobiliary, not the seven.

Joseph WY. Lau (Hong Kong): I just want to make a comment, I basically agree with Neuhaus and disagree with what S.T. Fan has said about the use of the nasobiliary catheter. I think with the trend of multiple stenting; the double pigtailed stent which I usually use is a 7-French. I think this is the space between the two stents is adequate to drain thick pus. Using I think, depending upon the pus, if it is so thick, then the addition of an endoscopic sphincterotomy would solve the issue. So in fact nowadays, in practice, I usually use a stent instead. Because, first of all, what Professor Tanaka mentioned about the accidental removal of the tube by the patient when they are confused, and also because of cutting the cost - a nasobiliary drainage is about four times more expensive than an endoscopic stent.

Chen-Guo Ker (Taiwan): In addition to the drainage effect, so we have to look at what is happening in the entire biliary duct, so therefore we have to perform a secondary, a second cholescintigraphy to look at what is happening in the entire biliary duct, so therefore ENBD is superior and first choice in my opinion.

Philippus C. Bornman: We are then going to vote on the second question, "Which procedure do you prefer, internal (tube stent) or external (nasobiliary drainage)?" Please vote with three options in mind, internal, external, and both.

Let us look at the Japanese consensus. Right, that is interesting. I think this is going to need some more discussion and I am not sure we can really do it now. I think we will record it and maybe we will have to refer it back to tomorrow, in terms of time, in the interests of time. But let us go on, we still have to look at the overseas consensus. Well, it looks very similar to me (refer to Fig. 2).

\section{Addition of EST}

Philippus C. Bornman: Right, we need to move on. The third question is "For biliary drainage, not for stone removal, do you prefer addition of EST?" and we have heard the data already, if it is a question of would you do a sphincterotomy at the time of the drainage? Yes; yes depending on the situation; and no. All right, shall we start with the voting?

Okay, that looks quite convincing, and the Japanese. ... So there we have a no, a yes in very little. Again, I think that time is catching up on us so we will take note of that and we will take it further. It is obviously very difficult to phrase these questions because there are so many variations, but I think we are getting the message (refer to Fig. 3).

\section{Timing of biliary drainage}

Satoshi Kondo (Japan): Let us hurry to the next issue about the timing of the biliary drainage. I believe that the timing of the biliary drainage depends on severity assessment, which was discussed in the morning session. Here is the summary, but this may be partially tentative.

This is a simple question about "The timing of biliary drainage for severe acute cholangitis." The options are: as soon as possible, or within $24 \mathrm{~h}$, or following conservative treatment unless the patient has worsened. The results are very similar for the Japanese and overseas. Okay, we reached a consensus (refer to Fig. 4).

Satoshi Kondo: The next question is "For moderate acute cholangitis, which is better, as soon as possible, within $24 \mathrm{~h}$, or following conservative treatment unless the patient worsened?"

This is the overseas panelists' result, it is a spilt. So we need more discussion, but we do not have enough time. Next please, the Japanese result. Again, we need more discussion tomorrow, especially about the definition of moderate acute cholangitis - that is important.

Steven Strasberg (USA): I think you might get a different result if you said within $12 \mathrm{~h}$ rather than within $24 \mathrm{~h}$, I think it would be easier to reach a consensus.

Henry A. Pitt: And even on the first question I think the question is do you stabilize the patient first and then do the procedure, or vice-versa. And that is a better question than the question that we asked.

Jacques Belghiti (France): In acute cholangitis, I would like to know what is the best method of emergency treatment in patients with moderate cholangitis. During the last year we saw many catastrophes by the surgeons going immediately operating the patient without establishing the hemodynamics. So I am very surprised that number one and number two is in $12 \mathrm{~h}$. We go immediately and do something without knowing. We know a lot of patients who improve themselves, spontaneously after antibiotic treatment. So I would like to go and have a further discussion on this point.

Thomas R. Gadacz (USA): I really disagree. This is, to me, still an emergent condition because it is very difficult to predict how these patients are going to respond. I think it is very important that we are defining acute 
cholangitis as infection with obstruction. And it is important to treat both. I would no longer be comfortable with simple emergency drainage without antibiotics than I would be with antibiotics and not emergency drainage. I think you have two key components here and I think the key surgical principles are that you treat both components. You treat the infection with antibiotics and you treat the obstruction with drainage. I am really surprised that you are willing to wait to see how a patient responds and this to me is a life-threatening condition.

Jacques Belghiti: Of course it seems logical what you say. But there is one paper from France showing clearly that if you operate too quickly on the patient, you have less good results than if you operate on the patient after resuscitation, and if you go too fast to the operating room, it has catastrophic results and so that is why I would be in favor to wait during drainage. I think we can discuss this point.

Philippus C. Bornman: I think, in the interests of clarity, you are not talking about surgical drainage or surgi- cal operation and we are talking about endoscopic drainage, so I think we need to make a clear distinction between the two.

Jacques Belghiti: Drainage for me could be the same as to operate, no, even just endoscopic, I would favor it. But I accept to be alone, do not worry.

Satoshi Kondo: Now we have changed the second option to within $12 \mathrm{~h}$, so now we vote about this question. This is the overseas panelists' result; split. Next, Japanese; it is completely split. Actually, the definition of moderate acute cholangitis is unclear now, not definite. So we will discuss tomorrow morning (refer to Fig. $5 \mathrm{a}, \mathrm{b})$.

Next, we are going to vote on "The timing of biliary drainage for mild acute cholangitis?" This question might be complicated because, mild, the definition is not so clear. But it is almost consensus. Please, the only problem is moderate. Next, the Japanese; oh, we have reached a consensus (refer to Fig. 6).

We would like to close this session. Thank you for your cooperation. 